\title{
FITOTECNIA
}

\section{PRODUTIVIDADE DO CAFEEIRO E CULTIVOS INTERCALARES SOB DIFERENTES REGIMES HÍDRICOS (1)}

\author{
ROGÉRIO TEIXEIRA DE FARIA ${ }^{(2)}$; RUBENS SIQUEIRA ${ }^{(2)}$
}

\begin{abstract}
RESUMO
O efeito de diferentes regimes hídricos na produtividade do cafeeiro e cultivos intercalares foi determinado em um experimento em Latossolo Vermelho distroférrico, em Londrina, PR, durante sete anos. Os tratamentos consistiram de aplicação de irrigação para manter a camada de solo de 0,7 m com mais de $50 \%$ da água disponível $(40 \mathrm{kPa}$ a $0,25 \mathrm{~m}$ ) e $30 \%$ de água disponível (70 kPa a 0,25 m), além de um tratamento não irrigado. Após o terceiro ano de implantação da lavoura, na fase reprodutiva do cafeeiro, a camada de manejo de irrigação foi aumentada para $1 \mathrm{~m}$ e os tratamentos irrigados foram desdobrados em dois tratamentos: com irrigação durante o ano todo e com irrigação de setembro a março. Durante os dois anos iniciais de formação da lavoura, foram cultivados feijão, seguido de arroz, intercalares ao cafeeiro. Em média, a irrigação aumentou a produtividade de café de $15 \%$ a $22 \%$, em relação à testemunha, quando aplicada no período de setembro-março, e em cerca de $10 \%$, quando aplicada durante o ano todo. A maturação, porém, foi mais desuniforme e não se eliminou o efeito bienal de variação da produção de café. Além de proporcionar produtividade significativamente superior à testemunha, com a irrigação aplicada de setembro a março, mantendo-se o solo com umidade acima de 30\% da água disponível (tensões menores que $70 \mathrm{kPa}$ a $0,25 \mathrm{~m}$ ), houve menor consumo de água que nos demais tratamentos irrigados. Para as culturas intercalares, a irrigação aumentou a produtividade de $240 \%$ a $300 \%$ para o feijão e em cerca de $50 \%$ para o arroz.
\end{abstract}

Palavras-chave: irrigação, café, umidade do solo.

\section{ABSTRACT \\ COFFE AND INTERCROPPING PRODUCTIVITIES UNDER DIFFERENT WATER REGIMES}

The effect of soil water regimes on coffee yield and intercropping species were assessed by an experiment conducted in a red dark Latosol, in Londrina, State of Paraná, Brazil. Treatments consisting on application of irrigation for maintaining soil moisture in the $0-0.7 \mathrm{~m}$ depth above $50 \%$ soil available water $(40 \mathrm{kPa}$ at $0.25 \mathrm{~m})$ and $70 \%$ soil available water $(70 \mathrm{kPa}$ at $0.25 \mathrm{~m})$, in addition to a non irrigated treatment, were evaluated during seven years. During coffee reproductive stage, the irrigation

(1) Recebido para publicação em 15 de abril de 2004 e aceito em 31 de outubro de 2005.

( $\left.{ }^{2}\right)$ Instituto Agronômico do Paraná, Área de Engenharia Agrícola, Caixa Postal 481, 86001-970 Londrina (PR). E-mail: rtfaria@iapar.br 
management depth was extended to $1 \mathrm{~m}$ and irrigated treatments were split into irrigation during the whole year and irrigation from September to March. During the first two years, dry beans followed by rice were cultivated intercropping to the coffee crop. The mean results over the years revealed coffee yield increases from $15 \%$ to $22 \%$ over the non irrigated treatment, when irrigation was applied from September to March, and about $10 \%$, when applied during the whole year, however maturation was more uniform and there was no differences in interanual yield variability. The treatment consisting in irrigation applied from September to March, maintaining soil above $30 \%$ available water (70 $\mathrm{kPa}$ at $0.25 \mathrm{~m}$ ), lead to low water requirement as compared with other irrigated treatments. For intercropping, irrigation increased dry bean yield by 240 to $300 \%$ and for rice yield by about $50 \%$.

Key words: irrigation, coffee, soil moisture.

\section{INTRODUÇÃO}

A cafeicultura paranaense segue o modelo de produção que se baseia no uso de tecnologias que possibilitam a auto-sustentação da propriedade, incluindo a diversificação, alta eficiência produtiva, melhoria da qualidade do produto e melhor aproveitamento dos recursos naturais (IAPAR, 1991).

Com a ocorrência de freqüentes geadas no Estado do Paraná, há tendências do cultivo do cafeeiro em pequenas áreas, em cultivo adensado. Além das implicações de mecanização da lavoura devidas à adoção dessa técnica (ANDrocioli Filho e Siqueira, 1993), há evidências que o aumento da população de plantas possa afetar significativamente os componentes do balanço hídrico, devido ao aumento da área foliar (DOOREMBOS e KASSAM, 1979). O consumo de água pode ser também influenciado pelo cultivo intercalar ao cafeeiro, recomendado na fase inicial da lavoura, visando obter receita extra durante os anos sem produção de café (IAPAR, 1991).

No Paraná, observa-se na região cafeeira boa disponibilidade de chuvas, com deficiência hídrica anual média inferior a $50 \mathrm{~mm}$, quando se assume a capacidade de armazenamento de água no solo de 100 $\mathrm{mm}$, o que é considerado altamente satisfatório para o desenvolvimento da cultura do café (CARAMORI et al., 2003). No entanto, períodos sem chuvas de curta duração ocorrem com freqüência elevada, acarretando eventuais decréscimos de produtividade da cultura.

Embora a irrigação seja restrita a umas poucas lavouras no Estado do Paraná, sua utilização em maior escala poderá ocorrer se for comprovado que a suplementação de água à cultura durante períodos de deficiência hídrica possibilita aumentar e/ou estabilizar a produtividade, proporcionando rendimentos suficientes para custear as despesas de investimento e operacionais da irrigação. Experimentos para avaliar os benefícios da irrigação têm sido desenvolvidos em várias regiões do Brasil, com resultados dependentes principalmente da disponibilidade hídrica da região (Tosselo et al., 1967, BARreto et al., 1974, KarASAWA et al., 2002, Gomes et al., 2003).

Além da produtividade, a irrigação pode afetar a maturação dos frutos (Gomes, 2003) e, conseqüentemente, a qualidade da bebida do café, devido à influência na época e número de floradas (Magalhães e Angelocci, 1976). Recentemente, RoDRIGUEs et al. (2003) demonstraram a possibilidade de sincronizar a florada do cafeeiro com botões florais quiescentes, irrigando plantas com tensão de água na folha acima de $2 \mathrm{MPa}$.

Na Região Norte do Paraná há compatibilidade de ciclos de desenvolvimento para o cultivo do feijoeiro de agosto a novembro e do arroz de dezembro a março. Assim, o cultivo intercalar possibilita a obtenção de duas colheitas por ano, produzindo uma receita extra durante a fase de formação do cafeeiro. Em tal sistema, apesar das vantagens, há limitações de deficiência hídrica, visto que é freqüente a ocorrência de baixas precipitações pluviais ou "veranicos" em agosto, no início do ciclo do feijoeiro, e fevereiro e março, na fase reprodutiva do arroz (CARAMORI e FARIA, 1987). A deficiência hídrica, associada à elevada população de plantas no sistema intercalar e à suscetibilidade ao estresse hídrico das culturas anuais, pode causar sérios danos na produção, eliminando suas vantagens. Ademais, a falta de chuvas durante certos períodos pode prejudicar o crescimento inicial do cafeeiro, induzindo a menores colheitas na fase de produção.

Para recomendar a prática de irrigação aos cafeicultores paranaenses, há que se avaliar sua economicidade, o que requer dados quantitativos da resposta de produtividade da cultura à aplicação de água, obtidos com a adoção de práticas de manejo de água que proporcionem os maiores rendimentos e melhor eficiência de uso de água. Além dos efeitos na produtividade, há necessidade de se avaliar também eventuais conseqüências da irrigação na qualidade do produto colhido e no manejo da cultura, tais como a desuniformidade de maturação, conforme estudado no presente trabalho. 


\section{MATERIAL E MÉTODOS}

O experimento foi desenvolvido no Centro Experimental do Instituto Agronômico do Paraná, em Londrina (PR), latitude $23^{\circ} 23^{\prime} \mathrm{S}$, longitude $51^{\circ} 11^{\prime} \mathrm{W}$ e altitude $550 \mathrm{~m}$, em Latossolo Vermelho distroférrico, textura argilosa, muito profundo, relevo plano a suavemente ondulado, boa drenagem em todos os horizontes. Pela análise química inicial do solo observou-se acidez elevada, devido a teores elevados de alumínio e baixos teores de cálcio e magnésio, concentração de fósforo insuficiente e médios teores de potássio e matéria orgânica. A retenção de água no solo é considerada média, com a maior parte da água disponível retida a baixas tensões (FARIA e CARAMORI, 1986). O clima da região é do tipo subtropical úmido, do tipo $\mathrm{Cfa}$, caracterizado por verões quentes e invernos frescos, com geadas ocasionais, ocorrendo concentração da precipitação no período de outubro a março, porém sem deficiência hídrica média anual pronunciada (CARAMORI et al., 2003)

O experimento constituiu-se de blocos ao acaso com quatro repetições, em parcelas com dimensões de $12 \mathrm{~m} \times 12 \mathrm{~m}$, sendo considerado como bordadura $3 \mathrm{~m}$ lateral à parcela. Os tratamentos consistiram de três regimes hídricos durante a fase inicial e de seis regimes hídricos na fase de lavoura formada, obtidos pela aplicação de irrigação sob diferentes níveis de retenção de água, de acordo com o seguinte:

a) Fase de formação da lavoura:

- Manutenção da umidade do solo na camada 0,7 $\mathrm{m}$ acima de $50 \%$ de água disponível (50AD);

- Manutenção da umidade do solo na camada 0,7 $\mathrm{m}$ acima de $30 \%$ de água disponível (30AD);

- Regime hídrico natural ou testemunha (T).

b) Fase de produção:

A camada de manejo da irrigação foi estendida para $1 \mathrm{~m}$ e os tratamentos irrigados desdobraram-se em tratamentos com irrigação durante o ano todo (50AD e 30AD) e com irrigação de setembro a março (50AD-SM e 30AD-SM), mantendose o tratamento-testemunha.

A cultivar Catuaí vermelho foi plantada em maio de 1981 no espaçamento de $2,5 \mathrm{~m}$ por $2 \mathrm{~m}$, com duas plantas por cova 4.000 plantas ha ${ }^{-1}$. Foi aplicado calcário dolomítico $\left(5 \mathrm{t} \mathrm{ha}^{-1}\right)$ antes do plantio e durante o desenvolvimento da lavoura, juntamente com a adubação química, conforme comprovada a necessidade em análise do solo realizada anualmente. Foram aplicados 2,5 $\mathrm{t} \mathrm{ha}^{-1}$ de esterco de curral, juntamente com superfosfato simples e cloreto de potássio em doses de 100 e $80 \mathrm{~kg} \mathrm{ha}^{-1}$ de $\mathrm{P}_{2} \mathrm{O}_{5}$ e $\mathrm{K}_{2} \mathrm{O}$ na cova de plantio; durante o segundo e terceiro ano aplicaram-se uréia, superfosfato simples e cloreto de potássio nas doses de 60, 0 e $30 \mathrm{~kg} \mathrm{ha}^{-1}$ de $\mathrm{N}, \mathrm{P}_{2} \mathrm{O}_{5}$ e $\mathrm{K}_{2} \mathrm{O}$ e, a partir do quarto ano até o fim do experimento, foram aplicados 300, 100 e $300 \mathrm{~kg} \mathrm{ha}^{-1}$ de $\mathrm{N}, \mathrm{P}_{2} \mathrm{O}_{5}$ e $\mathrm{K}_{2} \mathrm{O}$, além de $1 \mathrm{t}$ $\mathrm{ha}^{-1}$ de calcário. Durante o período da cultura foram realizados controles de pragas, doenças e plantas daninhas, a fim de minimizar os efeitos na produtividade das plantas do experimento.

Nos dois primeiros anos de formação da lavoura, foram cultivados feijão (cv. Carioca) e arroz (cv. IAC 164) nas entrelinhas do cafeeiro. No primeiro ano, foram semeadas quatro linhas de cada cultura, sendo o feijão semeado em julho no espaçamento de $0,5 \mathrm{~m}$ e densidade de 15 sementes $\mathrm{m}^{-1}$ e o arroz em dezembro no espaçamento de $0,5 \mathrm{~m} \times 50$ sementes $\mathrm{m}^{-1}$. No segundo ano foram semeadas duas linhas de cada cultura, sendo o feijão semeado em setembro e o arroz em dezembro.

As irrigações foram realizadas sempre que os tensiômetros acusaram tensões de água no solo de $40 \mathrm{kPa}$ e $70 \mathrm{kPa}$ para os tratamentos $50 \mathrm{AD}$ e $30 \mathrm{AD}$ respectivamente. Os aparelhos foram instalados a $0,25 \mathrm{~m}$ de profundidade na entrelinha do cafeeiro, no centro das parcelas. Para a fase de formação da lavoura, foram aplicadas lâminas de irrigação de 28 e $43 \mathrm{~mm}$ nos tratamentos 50AD e $30 \mathrm{AD}$ respectivamente, assumindo-se $0,7 \mathrm{~m}$ como profundidade de controle da irrigação. A partir do terceiro ano após o plantio, as lâminas de irrigação passaram a $45 \mathrm{~mm}$ e $63 \mathrm{~mm}$, para os tratamentos 50AD e 30AD respectivamente, assumindo-se a profundidade de controle da irrigação de $1 \mathrm{~m}$. As lâminas de irrigação foram calculadas utilizandose as curvas de retenção de água do solo determinadas na área experimental (FARIA e CARAMORI, 1986).

As irrigações foram aplicadas por aspersão, utilizando-se aspersores setoriais marca Samoto AJ34, espaçados de $12 \mathrm{~m} \times 12 \mathrm{~m}$ e operados com pressão de $300 \mathrm{kPa}$. Durante as irrigações, a pressão foi limitada por um regulador de pressão e a quantidade de água aplicada foi dosada por uma válvula métrica instalada em um cabeçal de controle, ao lado da área experimental. Para evitar escorrimento superficial devido à precipitação excessiva, a lâmina de irrigação requerida em cada tratamento foi aplicada em duas etapas, sendo metade feita por dois aspersores posicionados diagonalmente em cada canto da parcela e metade aplicada imediatamente após a mudança dos aspersores para as posições opostas na parcela. 


\section{RESULTADOS E DISCUSSÃO}

\section{Condições hídricas}

Os valores anuais de precipitação pluvial, evapotranspiração de referência calculada pelo método de Penman-Monteith e irrigação durante os sete anos do experimento são apresentados na tabela 1. Pelos resultados, observa-se que houve deficiência hídrica severa no período de agosto de 1985 a julho de 1986, deficiência hídrica moderada nos períodos de julho a agosto de 1981/82 e 1984/85 e ausência de deficiência no período restante.

A demanda por irrigação foi mais elevada durante os períodos com maior deficiência hídrica e nos tratamentos com regime hídrico com reposição a $50 \%$ da água disponível, em comparação com o tratamento com reposição a 30\% da água disponível. Também houve maior necessidade de irrigação nos tratamentos com irrigação durante o ano todo, em relação aos com aplicação de setembro a março. Assim, no período mais seco (agosto de 1985 a julho de 1986), nos tratamentos mantidos sob irrigação durante o ano todo, foram aplicados $450 \mathrm{~mm}$ (10 aplicações) no regime hídrico 50AD e $315 \mathrm{~mm}$ (6 aplicações) no 30AD. Quando as irrigações foram realizadas somente de setembro a março, as lâminas de irrigação diminuíram para $270 \mathrm{~mm}$ (6 aplicações) e $126 \mathrm{~mm}$ ( 2 aplicações) para os tratamentos 50AD e $30 \mathrm{AD}$ respectivamente. Em anos com elevada precipitação pluvial, como em 1986/87, os tratamentos 50AD demandaram $35 \mathrm{~mm}$ (3 aplicações) e não houve irrigação nos tratamentos 30AD.

Para representar a disponibilidade hídrica no solo, resultante dos efeitos dos tratamentos durante períodos representativos, são apresentadas na figura 1 os valores de tensão de água no solo medidos a 0,25 e $0,85 \mathrm{~m}$, durante os anos agrícolas de 1982/83 e $1985 / 86$, que corresponderam ao período mais chuvoso e mais seco respectivamente. Nos demais períodos compreendidos pelo estudo, verificaram-se condições mais próximas dos resultados do ano agrícola 1982/83 do que os obtidos para 1985/86.

Assim, com exceção do ano agrícola 1985/86, a tensão de umidade do solo foi elevada somente no tratamento testemunha, durante curtos períodos de deficiência hídrica, que ocorreram com maior frequência na camada superficial, como representado para o ano 1982/83 (Figura 1a). No ano agrícola 1985/86 ocorreu um por longo período de deficiência hídrica, que se iniciou em junho de 1985 e se prolongou até meados de fevereiro de 1986, com breve interrupção em decorrência de chuvas fracas em meados de novembro, mas que foram suficientes para diminuir momentaneamente a tensão de água do solo nas camadas superficiais do tratamento testemunha (Figura 1b). Com a normalização do regime hídrico, a partir de meados de fevereiro de 1986, ocorreu deficiência hídrica de baixa severidade durante curto período em abril e julho daquele ano.

Tabela 1. Chuva, evapotranspiração de referência (ETo), lâmina de irrigação e número de aplicações de irrigação, de acordo com os tratamentos, em sete anos de manejo do experimento

\begin{tabular}{|c|c|c|c|c|c|c|}
\hline \multirow{2}{*}{ Período } & \multirow{2}{*}{ Chuva } & \multirow{2}{*}{ ETo } & \multicolumn{4}{|c|}{ Lâmina de irrigação (n. ${ }^{\circ}$ de aplicações) } \\
\hline & & & $50 \mathrm{AD}$ & 50AD SM & $30 \mathrm{AD}$ & 30AD SM \\
\hline & & & 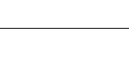 & 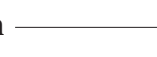 & & \\
\hline Agosto/1981 a julho/1982 & 1567 & 1343 & $336(12)$ & - & $378(9)$ & - \\
\hline Agosto/1982 a julho/1983 & 2139 & 1238 & $116(4)$ & $116(4)$ & 183(4) & $120(3)$ \\
\hline Agosto/1983 a julho/1984 & 1398 & 1397 & $465(11)$ & $195(5)$ & $335(6)$ & $78(2)$ \\
\hline Agosto/1984 a julho/1985 & 1499 & 1364 & $360(8)$ & $225(5)$ & $63(1)$ & $63(1)$ \\
\hline Agosto/1985 a julho /1986 & 997 & 1460 & $450(10)$ & $270(6)$ & $315(5)$ & $126(2)$ \\
\hline Agosto/1986 a julho/1987 & 1740 & 1326 & 135(3) & $135(3)$ & $0(0)$ & $0(0)$ \\
\hline Agosto/1987 a julho/1988 & 1718 & 1318 & $90(2)$ & $45(1)$ & $63(1)$ & $0(0)$ \\
\hline
\end{tabular}


a) $1982 / 83$
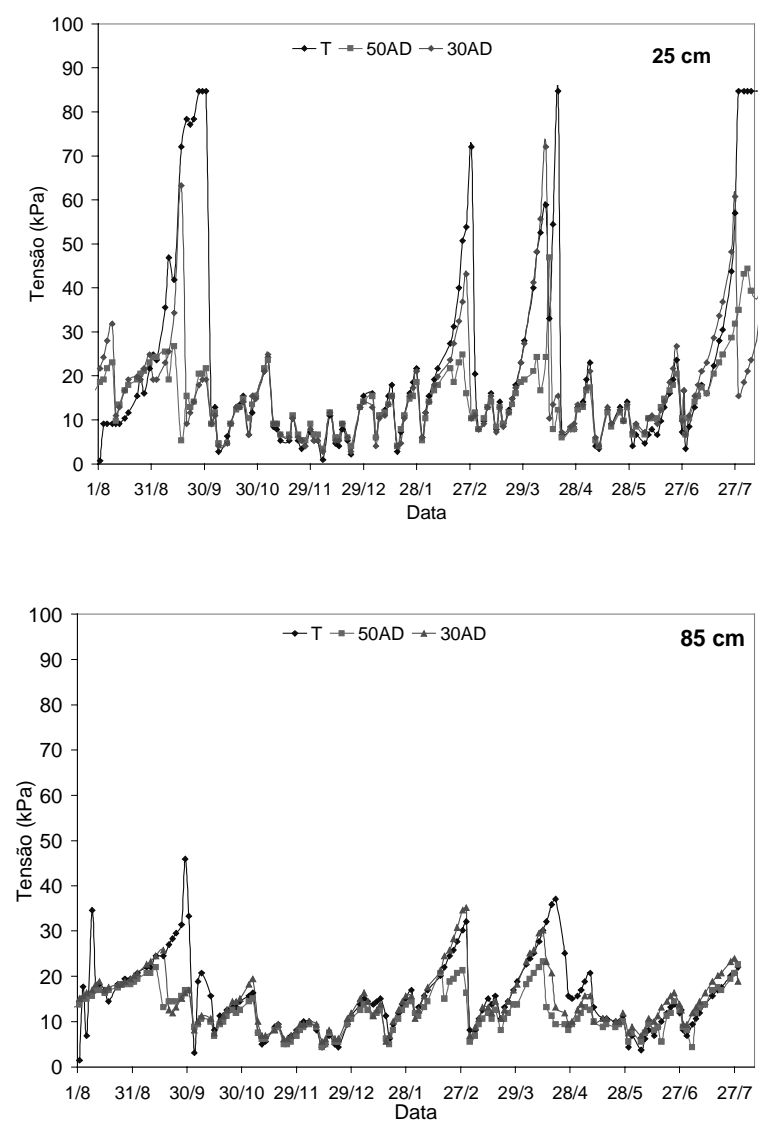

b) $1985 / 86$
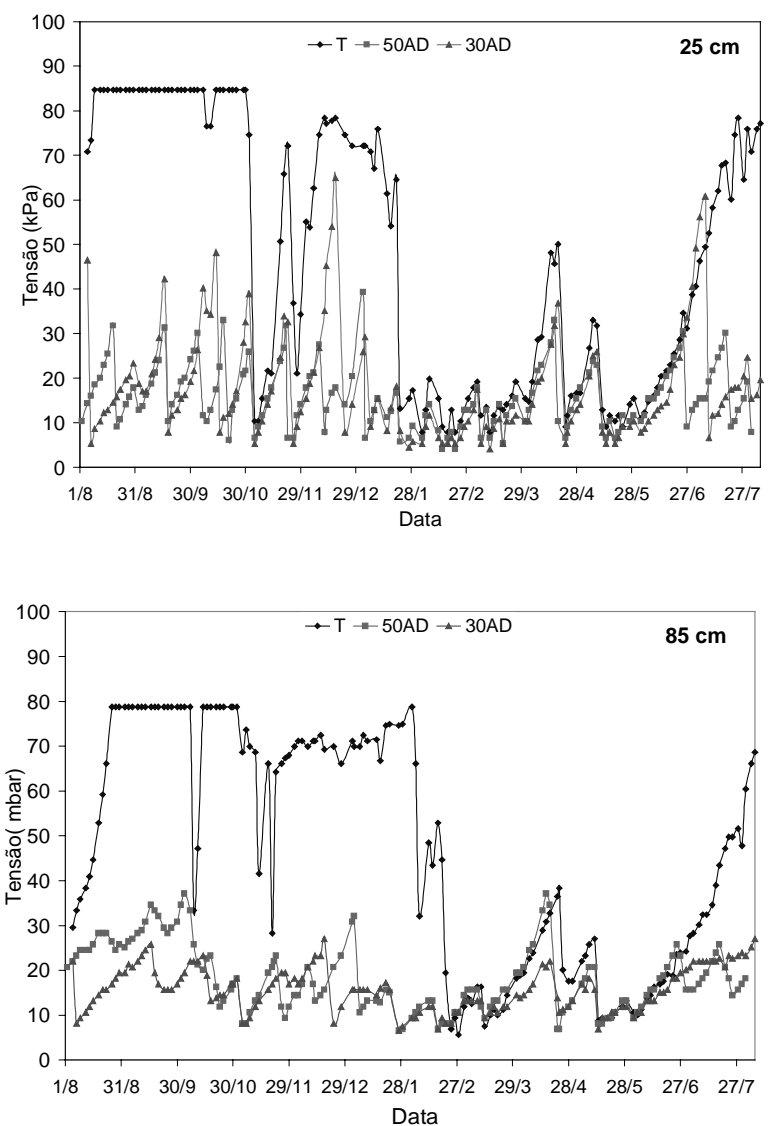

Figura 1. Tensão de água do solo em duas profundidades do perfil resultante dos regimes hídricos impostos, durante os períodos de agosto a julho de 1982/83 e 1985/86.

\section{Produtividade}

a) Culturas intercalares

O efeito da irrigação foi mais significativo na cultura do feijoeiro em decorrência da baixa precipitação pluvial durante a fase inicial de crescimento da cultura, ocorrida nos dois anos de cultivo. Para a cultura do arroz, constataram-se períodos de deficiência hídrica somente no primeiro ano (1981/82), durante o terceiro decêndio de janeiro, coincidindo com o período de perfilhamento/ emborrachamento. Consequentemente, os resultados mostrados na tabela 2 revelam produtividades estatisticamente superiores dos tratamentos com irrigação, durante os dois anos de cultivo de feijão e no primeiro ano de arroz, sobre o tratamento não irrigado. $\mathrm{O}$ incremento na produtividade de feijão no total dos dois anos de cultivo, de cerca de $300 \%$ e $240 \%$ para os tratamentos 50AD e 30AD, respectivamente, em relação à testemunha. Para o arroz, o incremento de produtividade em relação ao tratamento não irrigado foi de cerca de $50 \%$.

\section{b) Café}

A produtividade de café (Tabela 3 ) foi significativamente mais baixa em 1983 , por ser o primeiro ano de produção, e também em 1985, em conseqüência de geada moderada ocorrida em 26/ 08/1984, que causou morte de ponteiros e comprometeu a produtividade do ano seguinte. Nos demais anos a produtividade foi satisfatória, indicando boas condições de manejo do experimento e adoção de técnicas adequadas à lavoura. A maior média anual foi obtida em 1986, talvez devido à ausência de produção no ano anterior, embora se tenha verificado seca prolongada durante o segundo semestre de 1985. Médias intermediárias foram constatadas em 1984 e em 1987, seguidas de valores significativamente inferiores em 1988, que por outra vez foi prejudicada pela ocorrência de geada moderada no ano anterior.

$\mathrm{Na}$ análise conjunta das médias de produtividade de café durante as seis safras analisadas (Tabela 3), somente o tratamento 30AD-SM foi superior estatisticamente à testemunha. 
Tabela 2. Produtividade de feijão e arroz intercalares ao cafeeiro, durante os dois primeiros anos de formação da lavoura.

\begin{tabular}{|c|c|c|c|c|c|c|}
\hline \multirow{2}{*}{ Tratamento } & \multicolumn{3}{|c|}{ Feijão } & \multicolumn{3}{|c|}{ Arroz } \\
\hline & $1981^{*}$ & $1982^{* *}$ & Total & $1981^{*}$ & $1982^{* *}$ & Total \\
\hline & \multicolumn{6}{|c|}{$\mathrm{kg} \mathrm{ha}^{-1}$} \\
\hline $50 \mathrm{AD}$ & 790 a & 455 a & 1245 a & 3097 a & 879 a & 3976 a \\
\hline $30 \mathrm{AD}$ & $630 \mathrm{a}$ & 432 a & 1062 a & 3267 a & 844 a & $4111 \mathrm{a}$ \\
\hline $\mathrm{T}$ & $235 \mathrm{~b}$ & $76 \mathrm{~b}$ & $311 \mathrm{~b}$ & 1912 b & 710 a & $2622 b$ \\
\hline Média & 551 & 321 & 873 & 2758 & 811 & 3570 \\
\hline CV $(\%)$ & 25,9 & 40,6 & 31,4 & 9,2 & 27,3 & 13,4 \\
\hline
\end{tabular}

* resultado de 4 linhas de cultivo intercalar ao cafeeiro.

** resultado de 2 linhas de cultivo intercalar ao cafeeiro.

Médias seguidas da mesma letra não diferem entre si pelo teste Duncan 5\%

Tabela 3. Produtividade de café beneficiado e produtividade relativa (PR) no período de 1983 a 1988 em função dos tratamentos, em Londrina

\begin{tabular}{|c|c|c|c|c|c|c|c|c|}
\hline Tratamento & 1983 & 1984 & 1985 & 1986 & 1987 & 1988 & Média & PR \\
\hline & & & 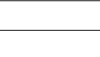 & Sc ha ${ }^{-1}$ & & & & $\%$ \\
\hline 50AD & $1,7 \mathrm{a}$ & $43,9 \mathrm{ab}$ & $2,1 \mathrm{a}$ & $54,1 \mathrm{a}$ & $43,8 \mathrm{a}$ & $17,7 \mathrm{a}$ & $27,2 \mathrm{ab}$ & 110 \\
\hline 50AD-SM & $1,4 \mathrm{a}$ & $51,1 \mathrm{a}$ & $1,3 \mathrm{a}$ & $56,2 a$ & $43,4 a$ & $16,5 \mathrm{a}$ & $28,3 \mathrm{ab}$ & 115 \\
\hline $30 \mathrm{AD}$ & $1,5 \mathrm{a}$ & $46,8 \mathrm{ab}$ & $1,3 \mathrm{a}$ & $47,7 \mathrm{a}$ & $46,5 a$ & $19,9 a$ & $27,3 a b$ & 111 \\
\hline 30AD-SM & $1,1 \mathrm{a}$ & $48,8 \mathrm{a}$ & $1,8 \mathrm{a}$ & $61,5 \mathrm{a}$ & $41,1 \mathrm{a}$ & $22,6 a$ & $30,0 \mathrm{a}$ & 122 \\
\hline $\mathrm{T}$ & $0,6 \mathrm{a}$ & $38,3 \mathrm{~b}$ & $2,2 \mathrm{a}$ & $49,9 a$ & $45,2 \mathrm{a}$ & $11,6 \mathrm{a}$ & $24,7 \mathrm{~b}$ & 100 \\
\hline Média & $1,3 \mathrm{~d}$ & $45,8 \mathrm{~b}$ & $1,8 \mathrm{~d}$ & $53,9 a$ & $44,0 \mathrm{~b}$ & $17,7 \mathrm{c}$ & 27,4 & - \\
\hline CV (\%) & 53,6 & 13,0 & 76,8 & 22,3 & 14,9 & 38,1 & 24,5 & - \\
\hline
\end{tabular}

Médias seguidas da mesma letra não diferem entre si pelo teste Duncan 5\%.

As médias dos tratamentos irrigados não diferiram entre si, porém, verificou-se tendência de maior produtividade dos tratamentos irrigados de setembro-março em relação aos tratamentos com irrigação durante o ano todo. Assim, tomando-se a testemunha como referência (nível 100), os acréscimos calculados pela produtividade relativa na tabela 3 demonstrou acréscimos de $20 \%$ para o tratamento $30 \mathrm{AD}-\mathrm{SM}, 15 \%$ para o $50 \mathrm{AD}-\mathrm{SM}$ e $10 \%$ e $11 \%$ para os tratamentos 30AD e 50AD, respectivamente. Deve-se destacar ainda que no tratamento 30AD-SM, além de proporcionar produtividade significativamente superior à testemunha, houve menor consumo de água que nos demais tratamentos irrigados (Tabela 1). Pela comparação das médias de produtividade dos tratamentos dentro dos vários anos (Tabela 3), observou-se diferença estatisticamente significativa somente em 1984, sendo os tratamentos irrigados no período de setembro-março (50AD-SM e 30AD-SM) superiores à testemunha, mas semelhantes aos tratamentos irrigados durante o ano todo (50AD e 30AD). Nesses, por sua vez, constataram-se médias mais elevadas que a testemunha, mas não houve diferença estatística. Nos demais anos, apesar da ausência de significância estatística, confirmou-se a tendência de maior produtividade nos tratamentos irrigados de setembro-março, principalmente do tratamento $30 \mathrm{AD}$, e menores médias para a testemunha.

Os níveis de produtividade obtidos com irrigação foram inferiores aos obtidos em experimentos desenvolvidos por SiLva et al. (2005) em Minas Gerais e Silva et al. (2004) no Rio de Janeiro, porém a baixa resposta à irrigação na maioria dos anos (Tabela 3) é compatível com outros experimentos 
realizados no Estado de São Paulo (Tosselo et al., 1967, BARREto et al., 1974, Karasawa et al., 2002). As diferenças de produtividade entre os tratamentos irrigados e testemunha deve-se à boa disponibilidade hídrica da região de Londrina e também à capacidade da planta extrair água em profundidade quando submetida ao estresse hídrico, abrandando esse efeito (FARIa e Siqueira, 2001).

Pelos resultados da tabela 3, verifica-se, ainda, que os regimes hídricos impostos pelos tratamentos não eliminaram o efeito bienal da produtividade. Assim, houve alternância da posição das médias dos tratamentos com o decorrer das colheitas, em que a alta produção em um ano foi seguida de menor produção no ano seguinte. Outros trabalhos de irrigação em cafeeiro também não reportam efeitos na estabilização interanual da produtividade (Tosselo et al., 1967), que é atribuído à competição entre frutos e estruturas vegetativas no ano de alta produção, ocorrendo favorecimento dos primeiros e decréscimo da produção no ano seguinte (RENA e MAESTRI, 1987).

Além do efeito na produtividade, a irrigação afetou o número de floradas do cafeeiro, como comprovado na safra 1985/86. Naquele período, a falta de chuvas durante a primavera atrasou a floração das plantas do tratamento-testemunha até meados de novembro, quando ocorreram chuvas fracas, mas suficientes para promover a abertura dos botões florais que permaneceram quiescentes desde setembro. Por outro lado, a ausência de deficiência hídrica devida à irrigação resultou em quatro floradas até novembro nos tratamentos irrigados. No entanto, apesar de apenas uma florada no tratamentotestemunha, houve bom pegamento de frutos, resultando em produções comparáveis a dos tratamentos irrigados na colheita de 1986. O retardamento da floração em presença de deficiência hídrica, como ocorrido no tratamento sem irrigação, constituiu um eficiente mecanismo de "escape" do cafeeiro para mitigar os efeitos do estresse hídrico na produtividade.

O aumento do número de floradas nos tratamentos irrigados resultou em maior desuniformidade de maturação de frutos, dada pela porcentagem de frutos verdes na época de colheita, em dois dos três anos de alta produção analisados (Tabela 4). As maiores médias de frutos verdes ocorreram nos tratamentos irrigados durante o ano todo, sendo essas superiores estatisticamente às médias do tratamento sem irrigação. As médias dos tratamentos irrigados de setembro a março foram menores que as médias dos tratamentos irrigados durante o ano todo e mais elevadas que a do tratamento não irrigado, porem não houve diferença estatística entre elas. De acordo com estudos da literatura (Gomes et al., 2003), os resultados obtidos nesse trabalho comprovaram que a ocorrência de estresse hídrico moderado durante o inverno, como ocorrido nos tratamentos testemunha e irrigados de setembro a março, é favorável para se obter colheitas de frutos com maturação mais uniforme.

Tabela 4. Percentagens de frutos verdes em anos de alta produção de café em função dos diferentes regimes hídricos submetidos.

\begin{tabular}{lccc}
\hline Tratamento & 1984 & 1986 & 1988 \\
\cline { 2 - 4 } 50AD & $28,6 \mathrm{a}$ & $10,0 \mathrm{a}$ & 22,5 \\
50AD SM & $21,4 \mathrm{ab}$ & $5,5 \mathrm{~b}$ & 19,5 \\
30AD & $20,5 \mathrm{ab}$ & $9,3 \mathrm{a}$ & 19,2 \\
30AD SM & $18,2 \mathrm{ab}$ & $6,7 \mathrm{~b}$ & 18,3 \\
T & $15,3 \mathrm{~b}$ & $7,0 \mathrm{~b}$ & 24,0 \\
Média & 20,8 & 7,7 & 20,7 \\
\hline
\end{tabular}

Médias seguidas da mesma letra não diferem entre si pelo teste Duncan 5\%

\section{CONCLUSÕES}

1. A irrigação proporcionou acréscimos médios de produtividade de café entre $15 \%$ e $22 \%$, em relação à testemunha, quando aplicada no período de setembro-março, e de cerca de $10 \%$, quando aplicada durante o ano todo. O menor consumo de água associado à melhor produtividade foi obtido no tratamento em que se manteve o solo com umidade acima de $30 \%$ da água disponível (tensões menores que $70 \mathrm{kPa}$ ), de setembro a março.

2. A irrigação não eliminou o efeito bienal de variação da produção de café e aplicação de água durante o ano todo causou maior desuniformidade de maturação devido ao aumento do número de floradas

3. No cultivo intercalar na fase de formação da lavoura, a irrigação incrementou em cerca de $240 \%$ a $300 \%$ a produção de feijão e em $50 \%$ a produção de arroz.

\section{REFERÊNCIAS}

ANDROCIOLI FILHO, A.; SIQUEIRA, R. O diâmetro da saia do cafeeiro como critério para ajuste de espaçamento. In: CONGRESSO BRASILEIRO DE PESQUISAS CAFEEIRAS, 19., Três Pontas, 1993. Resumos... Três Pontas: MAARA, 1993. p.16-17. 
BARRETO, G.B.; REIS, A.J.; ARRUDA, F.B. Experiência de irrigação de café novo - resultados da estação experimental de Ribeirão Preto. In: CONGRESSO BRASILEIRO DE PESQUISAS CAFEEIRA, 2., Poços de Caldas, 1974. Anais... Poços de Caldas: IBC-GERCA, 1974. p.320-323.

CARAMORI, P. H.; FARIA, R. T. Freqüência de períodos de 10 dias consecutivos com deficiência hídrica (veranicos) para Londrina e Ponta Grossa. Londrina: IAPAR, 1987. p.1-24. (IAPAR. Boletim Técnico, 20)

CARAMORI, P.H. etal. Zoneamento agrícola do Estado do Paraná, Londrina: Instituto Agronômico do Paraná, 2003. v. 1, 76p.

DOORENBOS, J.; KASSAM, A.M. Yield response to water. Rome, Italy: FAO, 1979. 139p. (FAO Irrigation and Drainage Paper, 33)

FARIA, R. T.; CARAMORI, P. H. Caracterização físico-hidrica de um Latossolo Roxo distrófico do município de Londrina, PR. Pesquisa Agropecuária Brasileira, Brasília, v. 21, p. 13031311, 1986.

FARIA, R. T.; SIQUEIRA, R. Extração de água do solo por cafeeiros irrigados e sem irrigação. In. CONBEA, 30., 2001, Foz do Iguaçu-PR. Anais... Jaboticabal-SP: Sociedade Brasileira de Engenharia Agrícola, 2001. (CDROM)

GOMES, M.C.R. et al. Efeito da irrigação na maturação do cafeeiro (Coffea arábica, L.). In: SIMPÓSIO DE PESQUISAS DE CAFÉS DO BRASIL, 3., 2003. Porto Seguro, 2003. Disponível em: www.embrapa.br/cafe/consorcio/colheita.htm. Acesso em: 21 ago 2005.

IAPAR. Modelo tecnológico para o café no Paraná. Londrina, 1991. 14p. (IAPAR. Informe de Pesquisa, 97)
KARASAWA, S., FARIA, M.A.; GUIMARÃES, R.J. Resposta do cafeeiro Cv. Topázio MG-1190 submetido a diferentes épocas de irrigação. Revista Brasileira de Engenharia Agrícola e Ambiental, Campina Grande, v.6, n.1, p28-34, 2002

MAGALHÃES, A.C.; ANGELOCCI, L.R. Sudden alteration in water balance associated with flower bud opening in coffee plants. Journal of Horticultural Science, Littlehampton, West Sussex, UK, v.51, n.3, p.419-423, 1976.

RENA, A.B.; MAESTRI, M. Ecofisiologia do cafeeiro. Piracicaba: Potafós, 1987, 249p.

RODRIGUES, G.C. et al.. Efeito do regime hídrico na floração de Coffea arábica, L. cv. Catuaí Rubi MG 1192. In: SIMPÓSIO DE PESQUISAS DE CAFÉS DO BRASIL, 3., 2003, Porto Seguro, 2003. Disponível em: www.embrapa.br/cafe/consorcio/ colheita.htm. Acesso em 21 ago 2005

SILVA, M.L.O. e al. Comportamento da produtividade acumulada de seis anos do cafeeiro (Coffea arábica, L.) sob diferentes lâminas de irrigação. In: SIMPÓSIO DE PESQUISAS DE CAFÉS DO BRASIL, 4., Londrina, 2005. (CDROM)

SILVA, M.G. et al. Produtividade do cafeeiro sob diferentes lâminas de irrigação, em quatro safras consecutivas. In: CONGRESSO BRASILEIRO DE PESQUISAS CAFEEIRAS, 30., 2004, São Lourenço. Trabalhos apresentados... São Lourenço: EMBRAPA, 2004. p. 345

TOSSELO, R.N. et al. Contribuição ao estudo da irrigação e restauração da lavoura velha do café da estação experimental de Botucatu. Pesquisa Agropecuária Brasileira, Brasília, v. 2, p.211-228, 1967. 